\title{
Conus Medullaris Teratoma with Utilization of Fiber Tractography: Case Report
}

\author{
Fahad Alkherayf ${ }^{1,2,3}$ Abdullah Faisal Arab ${ }^{1,4,5}$ Eve Tsai ${ }^{1,3}$
}

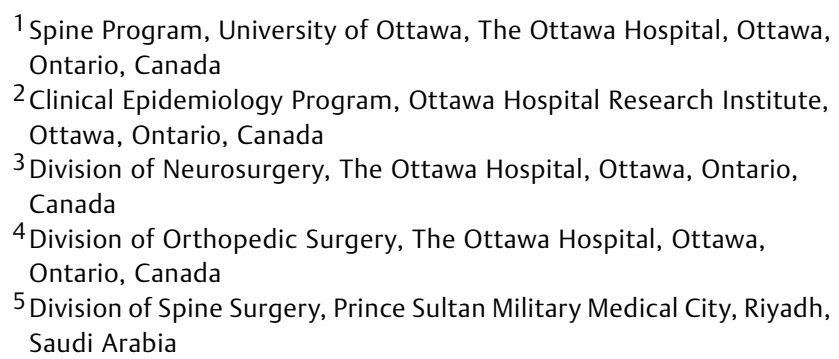

Address for correspondence Abdullah Arab, MD, Neurosurgery - Civic Campus, 1053 Carling Avenue, Ottawa, Ontario K1Y 4E9, Canada (e-mail: drabdullaharab@gmail.com).

J Neurol Surg Rep 2015;00:e183-e187.

\author{
Abstract \\ Keywords \\ - conus medullaris \\ - teratoma \\ - intramedullary tumor \\ - diffusion-weighted \\ images \\ - tractography
}

Objective Conus medullaris teratomas are very rare tumors. Traditional preoperative diagnosis depended on the findings from magnetic resonance imaging (MRI). Tractography is a novel technique that has recently been utilized to diagnose spinal cord lesions. This case report shows that fiber tractography has great potential in preoperative diagnosis and postoperative follow-up of teratomas of the conus medullaris.

Methods A 50-year-old man with a conus medullaris teratoma underwent tractography with the aim of visualizing the tumor in relation to the white matter tracts. The patient underwent a T12-L2 laminectomy, and the lesion was resected. The histopathology diagnosis was of a mature teratoma.

Study Design Case report.

Results Diffusion tensor imaging (DTI) and tractography provide more details about the white matter tracts in relation to space-occupying lesions that may be more sensitive than conventional MRI and have recently been utilized in spinal cord lesions. Fiber tracking has the ability to visualize the integrity of the white matter tracts at the level of the conus medullaris in relation to the lesion. The tracts appeared to be displaced by the lesion at the conus medullaris. Tractography also showed no white matter tracts within the lesion. Such findings are consistent with the characteristics of a benign lesion. Exploiting tractography in this case was helpful in predicting the nature of the lesion preoperatively and in planning the surgical intervention.

Conclusions Conus medullaris teratomas mostly affect adults. Patients generally present with a long history of clinical symptoms prior to diagnosis. Surgery is required for diagnosis, and the goal should be complete tumor excision without sacrificing any neurologic functions. The use of DTI and tractography, in addition to conventional MRI, has the potential to be very valuable for the diagnosis, surgical planning, and follow-up of patients with conus medullaris teratomas. received

December 23, 2014 accepted after revision April 28, 2015

published online

June 12, 2015
DOI http://dx.doi.org/

10.1055/s-0035-1555134. ISSN 2193-6366.
C 2015 Georg Thieme Verlag KG

Stuttgart · New York
License terms

(ㄷ) (i) $\ominus$ (\$) 


\section{Introduction}

Teratomas are composed of multiple tissues that are foreign to their location and lack organ specificity. They are uncommon tumors of the central nervous system and most commonly located in the pineal region. ${ }^{1} \mathrm{~A}$ true intramedullary teratoma of the conus medullaris is an extremely rare tumor. ${ }^{2}$ To our knowledge conus medullaris teratomas have been reported only 18 times in the literature. ${ }^{1-17}$ Their origin is controversial, and their natural history is less well known. ${ }^{5,13}$ Tractography is a new magnetic resonance imaging (MRI) technique that utilizes diffusion-weighted imaging (DWI) to delineate white matter (WM) tracts. ${ }^{18,19}$ We utilized tractography to determine whether this technique could lead to improved diagnosis compared with routine MRI. We report here on an adult patient with a conus medullaris teratoma who underwent tractography to study the spinal cord tracts in relation to the conus medullaris teratoma. To our knowledge, our report is the only case in the literature that includes an intraoperative view of a conus medullaris teratoma utilizing fiber tractography.

\section{Case Report}

\section{History and Physical Examination}

A 50-year-old man presented with a 2-year history of pain in the right groin, posterior thigh, and calf. His pain was associated with lateral right foot numbness. He also noted low back pain. The patient had been clinically diagnosed by his family doctor with degenerative disk disease and had undergone a trial of medical management and physical therapy. He then developed rectal numbness in addition to his right leg sensory symptoms and began to note a sensation of rectal pressure $\sim 8$ months before his presentation at our clinic. Five weeks prior to presentation he developed left lateral foot and calf numbness; he also noted left ankle plantar flexion weakness. He noted that coughing, sneezing, and lying flat in bed aggravated his back and leg pain, and stated that the pain would wake him up at night. He denied any bowel problems but did note intermittent bladder hesitancy. He had no upper extremity symptoms, and his past medical history was noncontributory.

On examination, muscle strength of his lower limbs was 5/5 from L2-S1, except he had 4/5 motor strength of his left ankle plantar flexion. His reflexes were increased at the knees and decreased at the ankles bilaterally. His toes were pointed down on the left and were equivocal on the right. Straight leg raising was 90 degrees bilaterally. Sensory examination was decreased to pinprick on the right buttock, posterior calf, bilateral heels, and lateral foot. Proprioception was intact bilaterally. Gait was normal for tandem, tiptoe, and on heels. However, he was unable to do a tandem gait with his eyes closed.

\section{Radiologic Evaluation}

MRI revealed an intramedullary conus lesion extending from the mid-L1 level to the mid-L2 level. The lesion measured $24 \times 15 \times 37 \mathrm{~mm}$ (-Fig. 1). The lesion contained a heterogeneous signal. The lesion was minimally hyperintense on $\mathrm{T} 1$ and was hypointense on T2; however, there was an area of T2 hypointensity along the posterior margin that was hyperintense on T1. There was an enhancing component at the inferior aspect of the lesion. This enhancing component measured $7 \mathrm{~mm}$ and had a nodular appearance.

\section{Fiber Tractography}

Imaging was performed on a 1.5-T Siemens MR imager. The protocol began with the acquisition of a sagittal T2-weighted fast spin-echo sequence. Subsequently, axial DWI single-shot
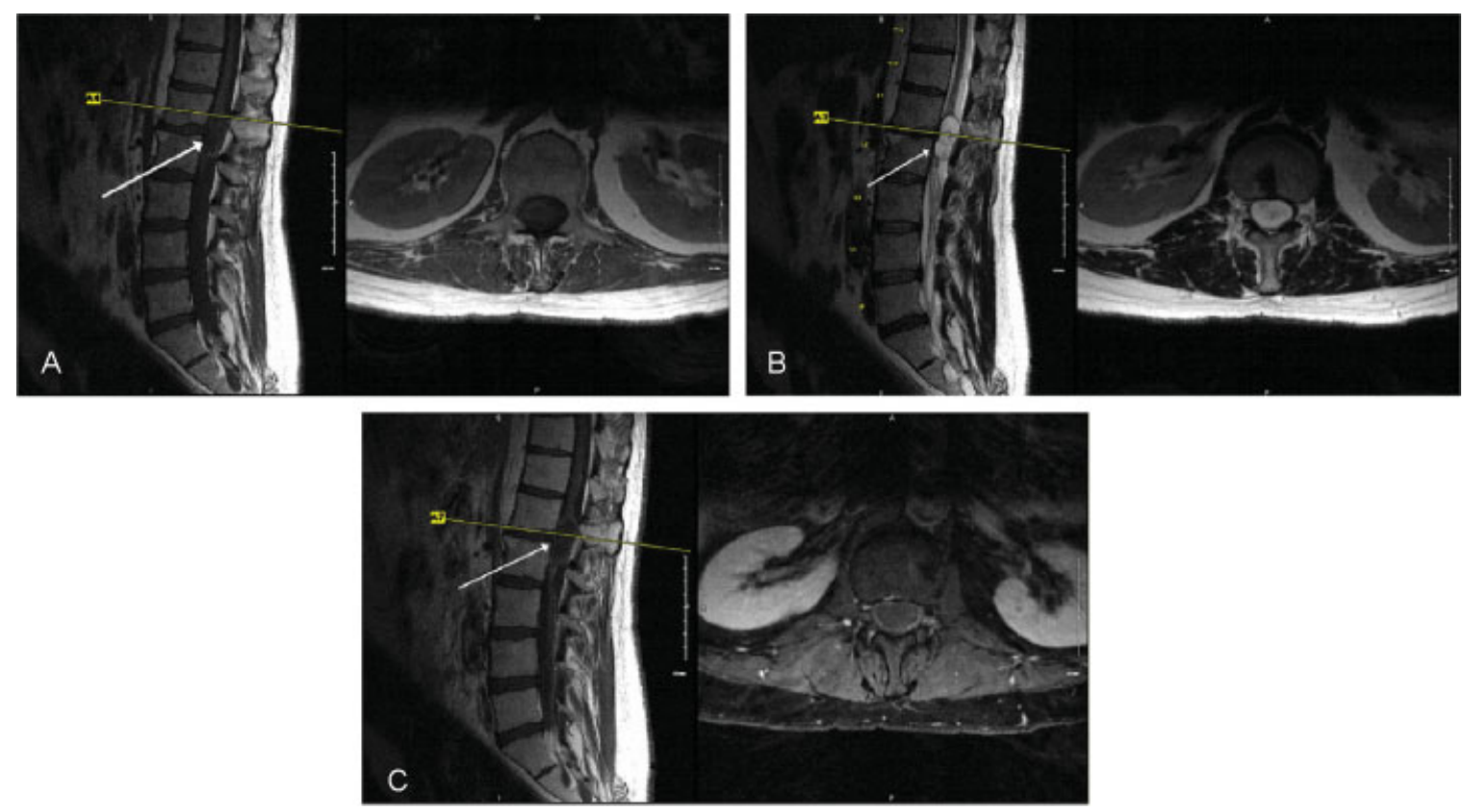

Fig. 1 Sagittal and axial magnetic resonance imaging. (A) T1, (B) T2, and (C) T1 with gadolinium sequences. Arrows indicate the lesion. 
echo-planar sequence using generalized autocalibrating partially parallel acquisition and 12 noncollinear gradient directions were obtained. The three-dimensional WM fiber tracts were created using the principal diffusion directions method where the eigenvector corresponding to the largest eigenvalue was extracted from the diffusion tensor generated from the diffusion tensor imaging (DTI) data sets in the region where the diffusion was linear. Typical values for the fractional anisotropy threshold and the angulation threshold were 0.17 and 45 degrees, respectively. MedINRIA v.1.8 and DTI Studio v.2.02 software were used to generate the fiber tracking images (-Fig. 2).

\section{Operative Course}

Given the lesion and the progressive symptoms without diagnosis, informed consent was obtained from the patient for an excisional biopsy. The patient was placed under general anesthesia and positioned prone on a Jackson table. He underwent a T12-L2 bilateral laminectomy. Intraoperative ultrasound was used to confirm that the rostral and caudal poles of the lesion were encompassed within the laminectomy site. A midline durotomy was performed. Of note, the dura and arachnoid were adherent to the lesion on the right dorsolateral aspect of the cord. With an incision of the arachnoid circumferentially around the adhesion, which was $\sim 5 \mathrm{~mm}$, we were able to obtain a plane between the cord and dura ( - Fig. 3). After the durotomy was complete, the conus medullaris was seen to be swollen and the vascular

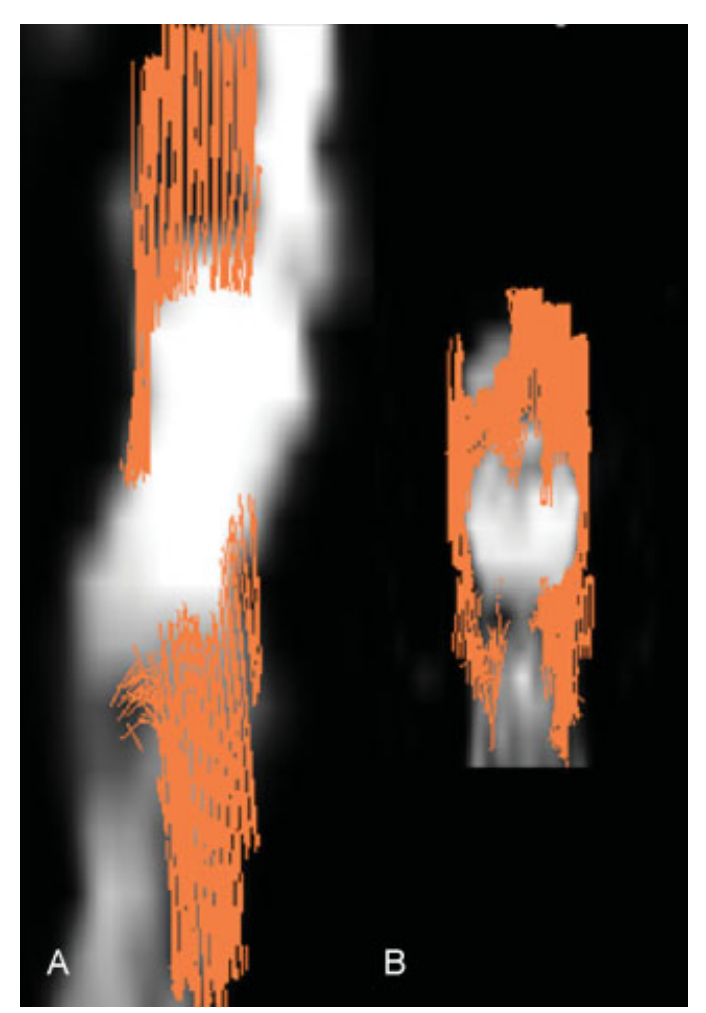

Fig. 2 (A) Sagittal and (B) coronal fiber tractography superimposed on diffusion-weighted images. This shows the white matter fiber tracts displaced by the tumor, which correlates with the benign nature of this lesion.
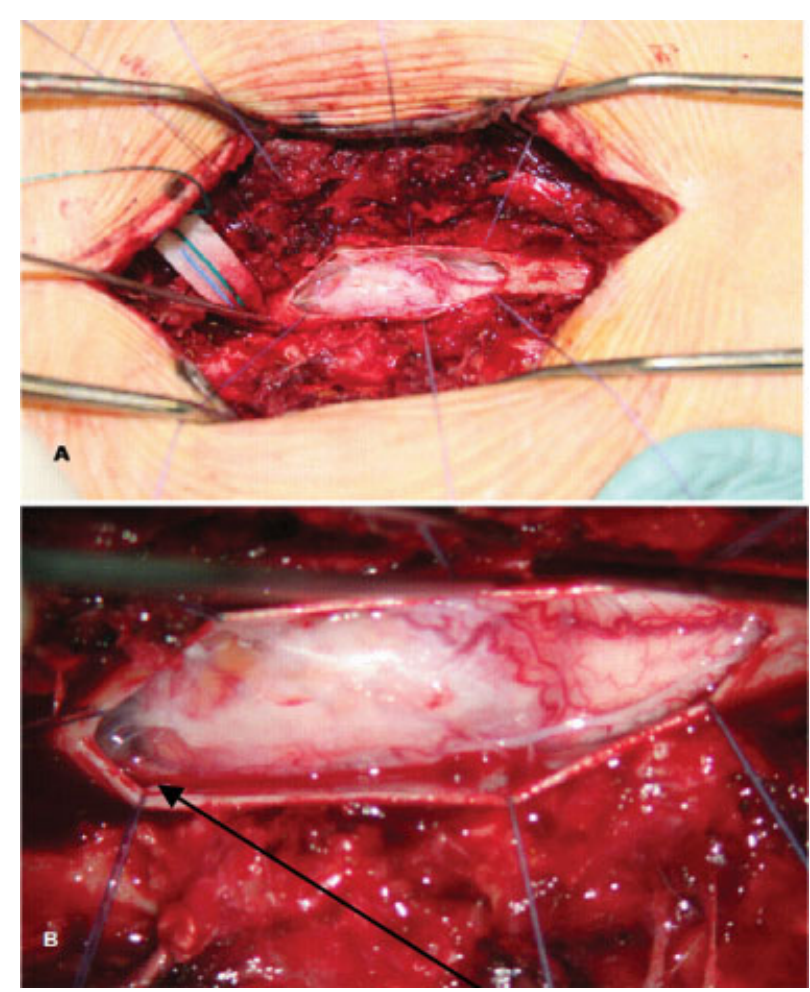

Fig. 3 ( A) The operative site and (B) the conus after durotomy but prior to tumor excision. Arrow indicates the thinned dorsum of the conus and the site of the myelotomy.

structures distorted on the right. The teratoma had thinned the dorsum of the conus medullaris on the left, which was visualized as a yellowed region. We performed a $4-\mathrm{mm}$ myelotomy at this thinned region and encountered a thick capsule. With incision of the capsule, clear fluid with white particles was expressed under moderate pressure. Once the cystic fluid was removed, pearly white tissue was removed with a Penfield 4 and biopsy forceps. After the pearly white tissue had been removed, the conus medullaris appeared to slacken and appeared to be less swollen. Samples were sent for pathology. At one point we visualized a light brown hair. We carefully inspected the tumor cavity walls and found two firm white nodules $\sim 2 \mathrm{~mm}$ in size in the ventral aspect of the tumor cavity. One nodule was easily resected circumferentially. The other nodule was adherent to the conus medullaris. After having received the quick section result as an epidermoid or benign lesion, we elected to leave the second nodule to avoid the risk of further neurologic deficits.

\section{Pathologic Examination}

Final microscopic examination revealed all three embryonic layers-the ectoderm, mesoderm, and endoderm-in the same lesion with no anaplasia (-Fig. 4).This confirmed the diagnosis of a mature conus medullaris teratoma.

\section{Discussion}

The word teratoma means malformation tumor, ${ }^{20}$ and a true intramedullary teratoma is extremely rare. Teratomas are 

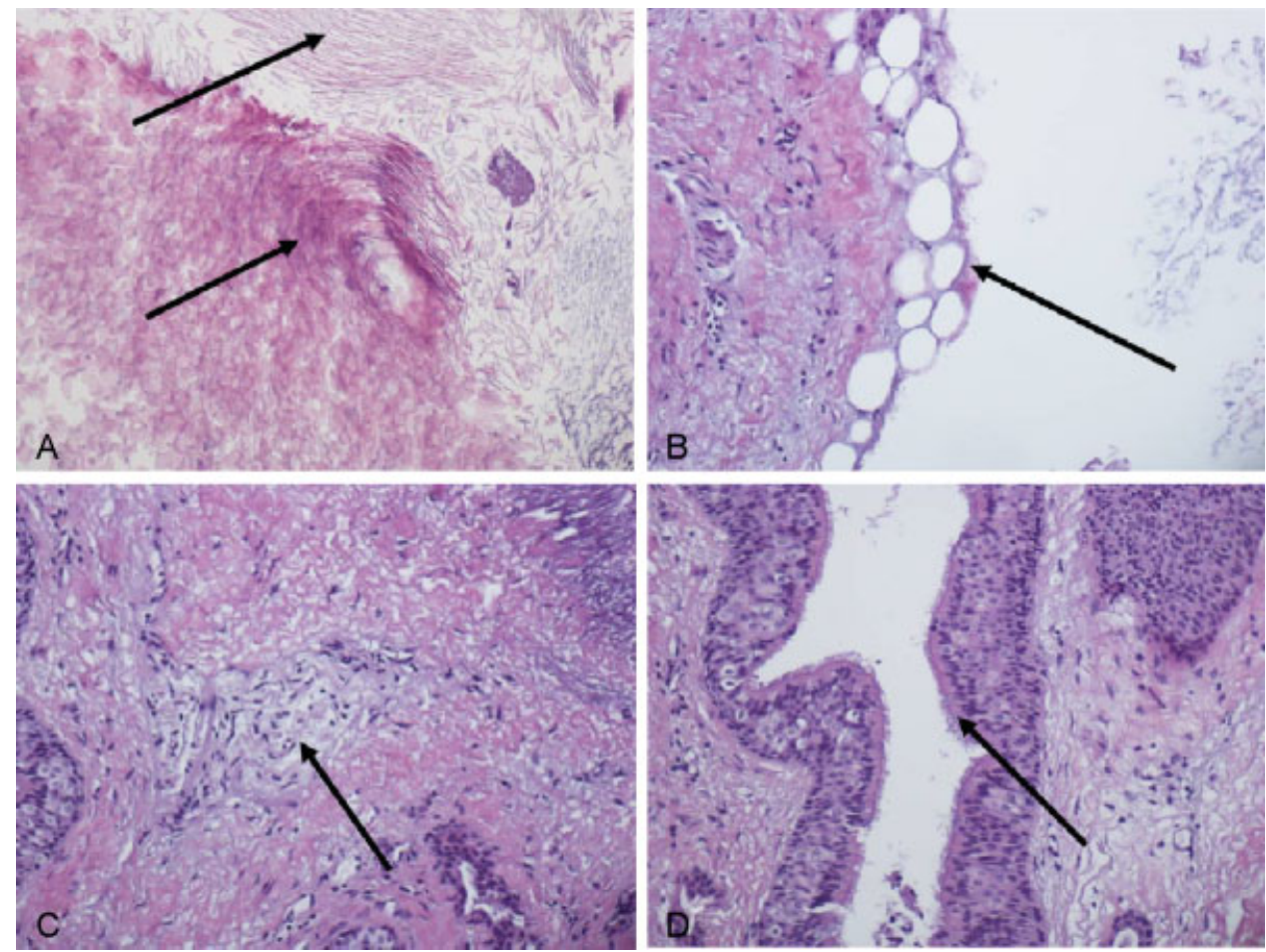

Fig. 4 Microscopic images of the operative specimen demonstrating lamellar keratin debris with a foci of (A) anucleate squames, (B) adipose tissue, (C) peripheral nerve elements, and (D) respiratory-type epithelium with ciliated goblet cells.

composed of multiple tissues that are foreign to their location and lack organ specificity. They are generally believed to originate from three germ cell layers-the ectoderm, mesoderm, and endoderm-which failed to migrate properly during early embryonic development. ${ }^{6}$ The ectodermal and mesodermal elements tend to overgrow at the expense of the endodermal elements. ${ }^{20}$ Because the finding of an immature or malignant teratoma is a pathologic diagnosis, the initial management of these tumors is surgical excision with

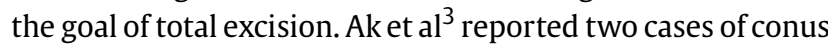
medullaris mature teratomas and reviewed an additional 20 patients with cervical, thoracic, and conus medullaris teratomas from the literature. They found a local recurrence rate of $10 \%$ in both total and subtotal excision. Within the last decade, adjuvant radiotherapy and chemotherapy have been added to the treatment scheme for many patients
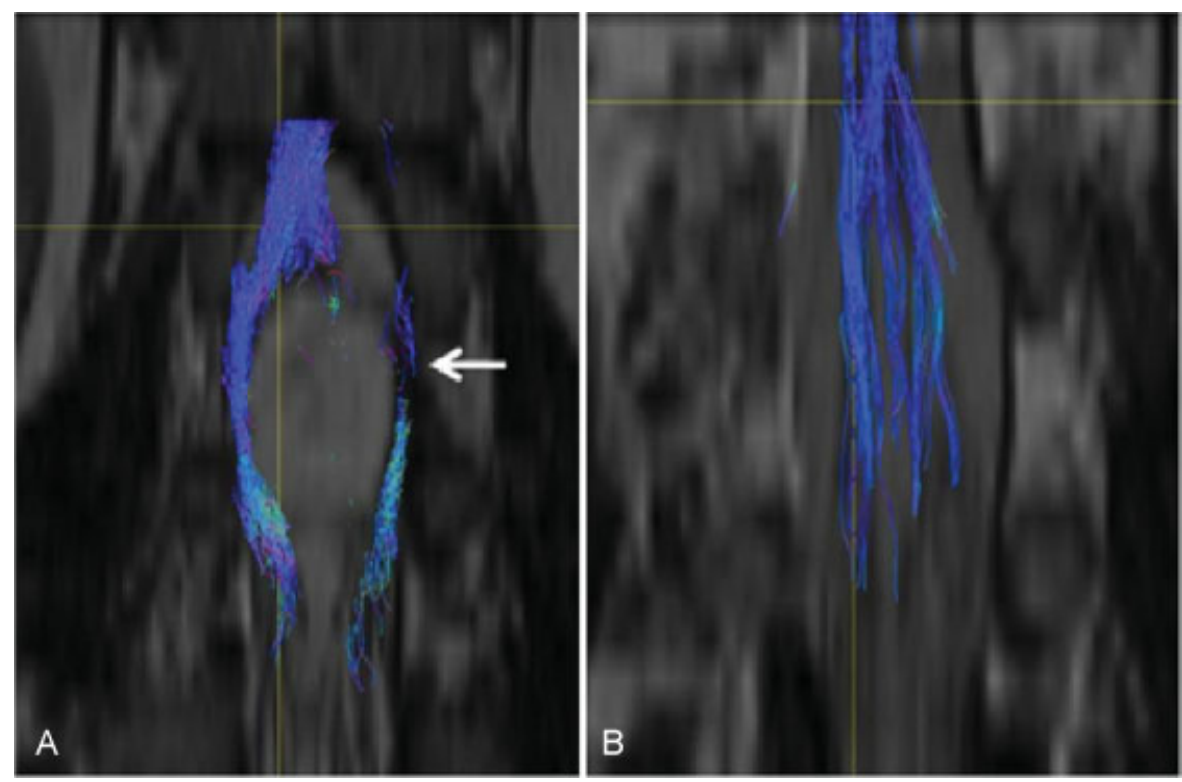

Fig. 5 (A) Preoperative and (B) postoperative coronal tractography showing complete resection of the tumor. 
with immature or malignant teratomas that could not be completely resected.

The clinical features do not differ from symptoms caused by other space-occupying lesions. In the conus medullaris area, lesions usually present with nerve root compression or cauda equina symptoms. ${ }^{1,10}$ Although conventional MRI is useful in localizing the lesion, it does not allow teratomas to be differentiated with certainty from other intramedullary lesions. Signal characteristics compatible with heterogeneous solid and cystic components and the presence of fatty tissue associated with congenital abnormalities favor the preoperative diagnosis of a teratoma. ${ }^{4,21}$ Because DTI and tractography provide more details about the WM tracts in relation to space-occupying lesions and may be more sensitive than conventional MRI, ${ }^{18,22}$ as well as being recently utilized in diagnosing spinal cord lesions, ${ }^{19,23,24}$ we also used these techniques to image a conus medullaris teratoma.

Fiber tracking offered the opportunity to visualize the integrity of the WM tracts at the conus medullaris level in relation to the lesion; these tracts seemed to be displaced by the lesion at the conus medullaris. Tractography also showed the absence of WM tracts within the lesion. These findings alluded preoperatively to the benign nature of the lesion. In this case tractography was helpful in predicting the nature of the lesion preoperatively and for planning the surgical intervention. In addition, tractography helped in deciding the location for the myelotomy, which is the area with no WM tracts (-Fig. 5).

\section{Conclusions}

Conus medullaris teratomas mostly affect adults. Patients generally present with a long history of clinical symptoms prior to diagnosis. Surgery is required for diagnosis, and the goal of surgery is complete excision of the teratoma without sacrificing any neurologic function. DTI and tractography, in addition to conventional MRI, potentially has great value in the diagnosis, surgical planning, and follow-up of patients with conus medullaris teratomas.

\section{References}

1 Kahilogullari G, Erdem A, Heper AO, Erden E. Intramedullary mature cystic teratoma of the conus medullaris. A case report. J Neurosurg Sci 2006;50(2):55-58

2 Mut M, Shaffrey ME, Bourne TD, Jagannathan J, Shaffrey CI. Unusual presentation of an adult intramedullary spinal teratoma with diplomyelia. Surg Neurol 2007;67(2):190-194

3 Ak H, Ulu MO, Sar M, Albayram S, Aydin S, Uzan M. Adult intramedullary mature teratoma of the spinal cord: review of the literature illustrated with an unusual example. Acta Neurochir (Wien) 2006;148(6):663-669; discussion 669

4 Ates O, Cayli SR, Koçak A, Alkan A, Onal C, Usta U. Mature spinal teratoma associated with thickened filum terminale. Neurol Med Chir (Tokyo) 2005;45(7):375-378
5 Bloch I, Varga Z, Benini A. Teratoma of the conus medullaris. J Clin Neurosci 1999;6(3):249-252

6 Caruso R, Antonelli M, Cervoni L, Salvati M. Intramedullary teratoma: case report and review of the literature. Tumori 1996; 82(6):616-620

7 Caruso R, Colonnese C. Intramedullary teratomas: Two case reports and a review of the literature. Zentralbl Neurochir 2006; 67(4):213-218

8 Eide PK, Skullerud K. Teratoma of the medullary cone as a cause of peripheral polyneuropathy [in Norwegian]. Tidsskr Nor Laegeforen 1994;114(10):1185-1186

9 Elmaci I, Dagcinar A, Ozgen S, Ekinci G, Pamir MN. Diastematomyelia and spinal teratoma in an adult. Case report. Neurosurg Focus 2001;10(1):ecp2

10 Fernández-Cornejo VJ, Martínez-Pérez M, Polo-García LA, Martínez-Lage JF, Poza M. Cystic mature teratoma of the filum terminale in an adult. Case report and review of the literature. Neurocirugia (Astur) 2004;15(3):290-293

11 Hader WJ, Steinbok P, Poskitt K, Hendson G. Intramedullary spinal teratoma and diastematomyelia. Case report and review of the literature. Pediatr Neurosurg 1999;30(3):140-145

12 Hejazi N, Witzmann A. Spinal intramedullary teratoma with exophytic components: report of two cases and review of the literature. Neurosurg Rev 2003;26(2):113-116

13 Mohindra S, Chhabra R, Gupta R, Dass Radotra B. Cystic, exophytic teratoma of conus medullaris presenting with chronic renal failure. Surg Neurol 2008;69(1):81-83; discussion 84

14 Natarajan M. Conus medullaris teratoma presenting as myokymia. Neurol India 1999;47(3):251

15 Nicoletti GF, Passanisi M, Platania N, Lanzafame S, Albanese V. Intramedullary spinal cystic teratoma of the conus medullaris with caudal exophytic development: case report. Surg Neurol 1994;41(2):106-111

16 Rosenbaum TJ, Soule EH, Onofrio BM. Teratomatous cyst of the spinal canal. Case report. J Neurosurg 1978;49(2):292-297

$17 \mathrm{Yu}$ J, Qu LM, Li Y, Huang H. Coexistence of spinal teratoma of the conus medullaris and arteriovenous malformation in an adult: a case report. Turk Neurosurg 2012;22(4):510-514

18 Ducreux D, Fillard P, Facon D, et al. Diffusion tensor magnetic resonance imaging and fiber tracking in spinal cord lesions: current and future indications. Neuroimaging Clin N Am 2007; 17(1):137-147

19 Thurnher MM, Law M. Diffusion-weighted imaging, diffusiontensor imaging, and fiber tractography of the spinal cord. Magn Reson Imaging Clin N Am 2009;17(2):225-244

20 Poeze M, Herpers MJ, Tjandra B, Freling G, Beuls EA. Intramedullary spinal teratoma presenting with urinary retention: case report and review of the literature. Neurosurgery 1999;45(2): 379-385

21 Monajati A, Spitzer RM, Wiley JL, Heggeness L. MR imaging of a spinal teratoma. J Comput Assist Tomogr 1986;10(2): 307-310

22 Vargas MI, Delavelle J, Jlassi H, et al. Clinical applications of diffusion tensor tractography of the spinal cord. Neuroradiology 2008;50(1):25-29

23 Tsuchiya K, Fujikawa A, Honya K, Nitatori T, Suzuki Y. Diffusion tensor tractography of the lower spinal cord. Neuroradiology 2008;50(3):221-225

24 Ozanne A, Krings T, Facon D, et al. MR diffusion tensor imaging and fiber tracking in spinal cord arteriovenous malformations: a preliminary study. AJNR Am J Neuroradiol 2007;28(7): 1271-1279 